\title{
SIKAP DAN PERILAKU PETANI PEDESAAN DALAM MENGAMBIL KEPUTUSAN MEMPEROLEH KREDIT USAHA TANI DI BANK KONVENSIONAL
}

\author{
Liza Khairani Harahap*, Luhut Sihombing**, Salmiah** \\ *) Alumni Prodi Agribisnis Fakultas Pertanian Universitas Sumatera Utara E-mail : \\ lizaahmad13.lh@gmail.com \\ **) Staf pengajar Prodi Agribisnis Fakultas Pertanian Universitas Sumatera Utara
}

\begin{abstract}
Abstrak
Tujuan penelitian ini untuk mengetahui sikap dan perilaku petani pedesaan dalam mengambil keputusan memperoleh kredit usaha tani, mengetahui tingkat pengetahuan petani terhadap kredit usaha tani, mengetahui bagaimana sikap perbankan terhadap calon nasabah petani yang tidak memiliki agunan di DesaPegagan Julu III. Metode penentuan daerah yang digunakan dalam penelitian ini adalah metode purposive area sampling. Pengambilan sampel dilakukan dengan metode simple random sampling dengan jumlah sampel sebanyak 30 sampel. Metode analisis yang digunakan adalah metode deskriptif. Hasil penelitian menunjukkan sikap petani terhadap kredit usaha tani positif dan perilaku petani memakai kredit usaha tani dengan persentase $80 \%$. Tingkat pengetahuan petani terhadap kredit usaha tani sangat baik dengan perolehan persentase $80 \%$.Sikap perbankan terhadap calon nasabah petani yang tidak memiliki agunan menolak dan menyarankan menggunakan kredit tanpa agunan (KTA).
\end{abstract}

Kata Kunci : Sikap, Perilaku dan Tingkat Pengetahuan.

\begin{abstract}
The purpose of this study is to determine the attitudes and behavior of rural farmers in making decisions about obtaining farm loans, knowing the level of knowledge of farmers on farm loans, knowing how the banking attitude towards prospective farmers who did not have collateral in PegaganJulu III Village.The method used to determining the area in this study is the purposive area sampling. Samplingdone using simple random sampling method with a total 30 samples. The analytical method used is descriptive method. The results showed that farmers' attitudes towards farming were positive and the behavior of farmers using farming credit was $80 \%$. The level of farmers' knowledge of farming credit is very good with the approval of $80 \%$. Banking attitude towards prospective buyers of Farmers who do not have collateral is reject it and recommend to using The Credit Without Collateral (KTA).
\end{abstract}

Keywords :Attitude, Behavior and Level of Knowledge.

Liza Khairani Harahap, Luhut Sihombing, Salmiah , 2019. Sikap Dan Perilaku Petani Pedesaan Dalam Mengambil Keputusan Memperoleh Kredit Usaha Tani Di Bank Konvensional, JSEP 15(1): 96 - 103. 


\section{Pendahuluan}

Bank dikenal sebagai lembaga keuangan yang kegiatan utamanya menerima simpanan giro, tabungan dan deposito. Dalam perjalanan selanjutnya bank juga dikenal sebagai tempat untuk meminjam uang atau kredit. Kegiatan bank yang kedua setelah menghimpun dana dari masyarakat adalah meyalurkan kembali dana tersebut kepada masyarakat yang disebut dengan alokasi dana atau kredit pada bank konvensional.

Bank juga disebut sebagai lembaga perantara keuangan atau Financial Intermeditary. Sebagai lembaga perantara keuangan, artinya bank menjembatani kebutuhan dua nasabah yang berbeda, satu pihak merupakan nasabah yang memiliki dana dan pihak lainnya merupakan nasabah yang membutuhkan dana. Bank menghimpun dana dari masyarakat dalam bentuk simpanan dan menyalurkannya dalam bentuk kredit. Fungsi lainnya adalah penyaluran dana kepada masyarakat dalam bentuk kredit atau dalam bentuk penempatan dana lainnya. Sebagian besar penyaluran dana kepada pihak ketiga ialah dalam bentuk kredit. Kebijakan Pemerintah di bidang perkreditan selama ini masih bersifat umum. Padahal dalam hal tertentu kredit pertanian sebenarnya memerlukan kebijakan yang bersifat spesifik. Selama ini tingkat bunganya masih relatif tinggi untuk pengembangan agribisnis yang kompetitif. Didalam buku Manajemen Perbankan (Ismail, 2011) Tujuan penelitian adalah untuk : 1. Untuk mengetahui sikap dan perilaku petani dalam memperoleh kredit usaha tani. 2. Untuk mengetahui bagaimana tingkat pengetahuan petani kredit usaha tani di bank konvensional. 3 . Untuk mengetahui bagaimana sikap perbankan terhadap calon nasabah petani yang tidak memiliki agunan. Pada tahun 1959 sejak pendirian Padi Sentra yang menangani masalah petanian, penyaluran dan pemberian kredit, pemerintah Indonesia mulai memperkenalkan kredit program bagi petani. Kredit yang diperkenalkan pemerintah tersebut bertujuan untuk pembelian saranan produksi dan uang untuk biaya hidup (cost of living). Prosedur pencarian kredit tersebut sebenarnya mudah, hanya memerlukan agunan berupa lahan sawah atau jaminan produksi padi yang akan dipanen. Karena kredit memerlukan agunan lahan sawah atau jaminan produksi yang akan dipanen, petani menjadi sulit untuk menyediakan agunan tersebut sehingga kredit sulit diakses oleh petani (Hasan,1979 dalam Lubis 2005). Sikap Menurut Oxford Advanced Learner Dictionary mencantumkan bahwa sikap (attitude) berasal dari bahasa Italia attitudine yaitu "Manner of placing or holding the body, dan way of feeling, thinking or behaving". Campbel (1950) dalam buku Notoadmodjo (2003, p.29) mengemukakan bahwa sikap adalah "A syndrome of response consistency with regard to social objects". Artinya sikap adalah sekumpulan respon yang konsisten terhadap obyek sosial. Dalam buku Notoadmodjo (2003, p.124) mengemukakan bahwa sikap (attitude) adalah merupakan reaksi atau respon yang masih tertutup dari seseorang terhadap stimulus atau obyek. Menurut Eagle dan Chaiken (1993) dalam buku A. Wawan dan Dewi M. (2010, p.20) mengemukakan bahwa sikap dapat diposisikan sebagai hasil evaluasi terhadap obyek sikap yang diekspresikan ke dalam prosesproses kognitif, afektif (emosi) dan perilaku. Dari definisi-definisi di atas menunjukkan bahwa secara garis besar sikap terdiri dari komponen kognitif (ide yang umumnya berkaitan dengan pembicaraan dan dipelajari), perilaku (cenderung mempengaruhi respon sesuai dan tidak sesuai) dan emosi (menyebabkan respon-respon yang konsisten). 
Pengetahuan didefinisikan sebagai segala sesuatu yang diketahui, atau segala sesuatu yang diketahui berkenaan dengan suatu hal. Pengetahuan adalah informasi yang telah dikombinasikan dengan pemahaman dan potensi untuk menindaki yang lantas melekat di benak seseorang. Pengetahuan adalah suatu perubahan dalam perilaku suatu individu yang berasal dari pengalaman nasabah adalah setiap orang pengguna jasa bank baik berupa simpanan maupun pinjaman dan segala bentu jasa bank. (Philip Kotler, 2002: 207).

Pola perilaku yang dimiliki nasabah dipengaruhi oleh pengetahuan mereka. Dengan tingkat pengetahuan yang dimilikinya, nasabah dapat memproses informasi yang baru, membuat pertimbangan dan mengambil keputusan. Dalam menghadapi penawaran jasa dari pihak bank, informasi yang dimiliki nasabah terhadap jasa kredit akan mempengaruhi perilaku. Ada tiga jenis pengetahuan nasabah, yaitu:

1. Pengetahuan tentang karakateristik jasa yang ditawarkan

2. Pengetahuan tentang manfaat jasa kredit, dan

3. Pengetahuan tentang nilai/kepuasan yang diberikan oleh jasa kredit.

Pengertian Keputusan Nasabah dalam Mengambil Kredit yaitu, sebuah proses keputusan mengambil kredit pada suatu bank (Philip Kotler, 2002: 207). Faktorfaktor yang Mempengaruhi Keputusan Nasabah dalam Mengambil Kredit. Adapun faktor-faktor yang mempengaruhi keputusan nasabah dalam mengambil kredit yaitu:

Faktor internal;

Faktor pribadi (Kotler, 2005:211) merupakan salah satu faktor yang mempengaruhi keputusan nasabah. Karakteristik ini meliputi usia, dan tahap siklus hidup, pekerjaan, situasi ekonomi, gaya hidup, pendapatan. Orang akan mengambil atau tidak suatu kredit akan disesuaikan dengan keadaan yang terus berubah.

Faktor Eksternal;

Faktor Sosial adalah faktor lingkungan sekitar nasabah yang terdiri dari kelompok rujukan dan keluarga. Rekan kerja, teman dan tetangga dapat dikategorikan menjadi kelompok rujukan yang 10 secara langsung maupun tidak langsung dapat mempengaruhi keputusan nasabah. Keluarga merupakan organisasi nasabah atau konsumen yang paling penting dalam masyarakat dan para anggota keluarga menjadi kelompok acuan primer yang paling berpengaruh. Keluarga terdiri atas orang tua dan anak-anak yang memiliki pengaruh dalam pengambilan keputusan pengambilan kredit yang ditawarkan oleh suatu bank atau lembaga keuangan lainnya.

\section{Metodologi}

Penelitian ini dilakukan di Desa Pegagan Julu III, Kecamatan Sumbul, Kabupaten Dairi. Daerah penelitian ini ditentukan secara purposive. Metode yang digunakan untuk menentukan besar sampel yaitu menggunakan metode slovin. Data yang dikumpulkan dalam penelitian ini terdiri dari data primer dan data skunder.

Untuk Identifikasi Masalah 1, yaitu untuk mengetahui, sikap dan perilaku nasabah dalam memperoleh kredit usaha tani digunakan metode analisis skala linkert. Yaitu dengan mencatat (tally) penguatan respon pada setiap pilihan jawaban atas suatu pernyataan positif ataupun negatif.

Untuk pernyataan positif, dapat diberikan skor untuk masing-masing pilihan jawaban dengan kategori seperti terlihat pada Tabel 1. 
Tabel 1. Kategori Jawaban Tentang Pernyataan Sikap Positif Petani Terhadap Kredit Usaha Tani (KUT)

\begin{tabular}{cll}
\hline No & \multicolumn{1}{c}{ Kategori Jawaban } & Skor \\
\hline 1. & SS (Sangat Setuju) & 5 \\
\hline 2. & S (Setuju) & 4 \\
\hline 3. & R (Ragu-Ragu) & 3 \\
\hline 4. & TS (Tidak Setuju) & 2 \\
\hline 5. & STS (Sangat Tidak Setuju) & 1 \\
\hline
\end{tabular}

Untuk pernyataan negatif juga diberikan skor untuk masing-masing pilihan jawaban dengan kategori seperti yang terlihat pada Tabel 2.

Tabel 2. Kategori Jawaban tentang Pernyataan Sikap Negatif Petani terhadap Kredit Usaha Tani (KUT)

\begin{tabular}{clc}
\hline No. & \multicolumn{1}{c}{ Kategori Jawaban } & Skor \\
\hline 1 & STS (Sangat Tidak Setuju) & 5 \\
\hline 2 & TS (Tidak Setuju) & 4 \\
\hline 3 & R (Ragu-Ragu) & 3 \\
\hline 4 & S (Setuju) & 2 \\
\hline 5 & SS (Sangat Setuju) & 1 \\
\hline
\end{tabular}

Rumus yang digunakan dalam mengukur sikap dengan menggunakan teknik skala Likert adalah sebagai berikut.

$$
\mathrm{T}=50+10\left[\frac{\mathrm{X}-\overline{\mathrm{X}}}{\mathrm{S}}\right]
$$

Keterangan:

$\mathrm{T}$ : Skor standar

$X$ : Skor responden

$\overline{\mathrm{X}}$ : Rata-rata skor kelompok

$S$ :Deviasi standar kelompok

Uji t, apabila:

$$
\begin{aligned}
& t \geq 50=\text { Sikap Positif } \\
& t<50=\text { Sikap Negatif }
\end{aligned}
$$

Berdasarkan uji $\mathrm{t}$ tersebut, dapat diketahui secara langsung sikap petani apakah positif atau negatif terhadap kredit usaha tani di daerah penelitian. Jika petani 
bersikap positif, maka itu menunjukkan bahwa kinerja KUT di daerah penelitian berjalan sesuai dengan yang diharapkan petani, dan sebaliknya jika petani bersikap negatif, maka itu menunjukkan bahwa KUT di daerah penlitian belum berjalan sesuai dengan yang diharapkan petani (Azwar, Saifuddin. 2007. Sikap Manusia.Pustaka Pelajar: Yogyakarta).

Perilaku petani dapat diketahui setelah wawancara langsung dilapangan, dalam hal ini ada dua macam perilaku, yaitu memakai kredit usaha tani atau tidak memakai.

Untuk Identifikasi Masalah 2, dalam menentukan tingkat pengetahuan petani terhadap mekanisme dan tatacara perolehan kredit di bank konvensional dianalisis dengan menggunakan metode pemberian skor.

Tabel 3. Jumlah indikator dan skor jawaban

\begin{tabular}{|c|c|c|c|}
\hline No & Indikator & Jawaban & Skor \\
\hline 1 & $\begin{array}{l}\text { KKP,KUR,KUT merupakan } \\
\text { program pijaman yang bisa } \\
\text { diakses untuk usaha tani. }\end{array}$ & $\begin{array}{c}\text { Ya } \\
\text { Tidak }\end{array}$ & $\begin{array}{l}2 \\
1\end{array}$ \\
\hline 2 & $\begin{array}{l}\text { Program kredit pemerintah yang } \\
\text { menetapkan bunga hanya } 5 \% \text {. }\end{array}$ & $\begin{array}{l}\text { Ya } \\
\text { Tidak }\end{array}$ & $\begin{array}{l}2 \\
1\end{array}$ \\
\hline 3 & $\begin{array}{l}\text { Program kredit pembiayaan } \\
\text { usaha tani jangka waktu } \\
\text { maksimal 5-6 tahun. }\end{array}$ & $\begin{array}{c}\text { Ya } \\
\text { Tidak }\end{array}$ & $\begin{array}{l}2 \\
1\end{array}$ \\
\hline 4 & $\begin{array}{l}\text { Lahan dapat menjadi agunan } \\
\text { usaha tani. }\end{array}$ & $\begin{array}{c}\text { Ya } \\
\text { Tidak }\end{array}$ & $\begin{array}{l}2 \\
1\end{array}$ \\
\hline 5. & $\begin{array}{l}\text { Angka plafon jumlah pinjaman } \\
\text { program kredit pembiayaan } \\
\text { usaha tani } \text { perseorangan } \\
\text { mencapai } 50 \text { juta. }\end{array}$ & $\begin{array}{c}\text { Ya } \\
\text { Tidak }\end{array}$ & $\begin{array}{l}2 \\
1\end{array}$ \\
\hline 6 & $\begin{array}{l}\text { Angka plafon jumlah pinjaman } \\
\text { program kredit usaha tani } \\
\text { kelompok tani mencapai } 500 \text { juta. }\end{array}$ & $\begin{array}{l}\text { Ya } \\
\text { Tidak }\end{array}$ & $\begin{array}{l}2 \\
1\end{array}$ \\
\hline 7 & $\begin{array}{l}\text { Pembayaran angsuran program } \\
\text { pinjaman/kredit bank ada yang } \\
\text { dapat dengan pembayaran } \\
\text { angsuran per periode panen.(jika } \\
\text { panen baru dibayar) }\end{array}$ & $\begin{array}{c}\text { Ya } \\
\text { Tidak }\end{array}$ & $\begin{array}{l}2 \\
1\end{array}$ \\
\hline
\end{tabular}

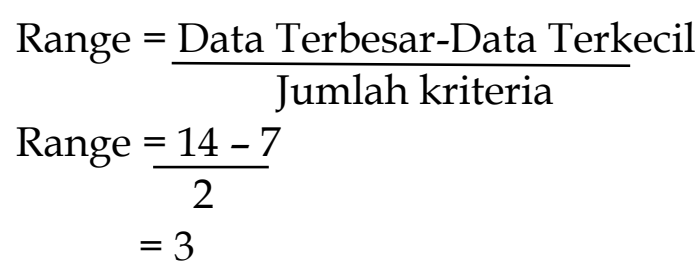

Jumlah skor tingkat pengetahuan petani terhadap perolehan kredit usaha tani antara lain 7 - 14 dengan range 3, sehingga dapat dikategorikan sebagai berikut :

$7-10=$ pengetahuan rendah

11- 14 = pengetahuan sangat baik 
- Jumlah pilihan $\quad=2$

- Jumlah pertanyaan $\quad=7$

- Skoring terendah $\quad=1$ (pilihan jawaban yang salah)

- Skoring tertinggi = 2 (pilihan jawaban yang benar)

Untuk Identifikasi Masalah 3, Bagaimana sikap perbankan terhadap petani yang tidak memiliki agunan digunakan metode deskriptif yaitu wawancara langsung dengan pihak bank tersebut.

\section{Hasil Dan Pembahasan}

\section{Hasil Analisis Sikap dan Perilaku Petani Dalam Memperoleh Kredit Usaha Tani.}

Hasil analisis sikap dan perilaku petani dalam memperoleh kredit usahatani di Desa Pegagan Julu III, Kecamatan Sumbul, Kabupaten menunjukkan sikap petani di daerah penelitian positif dengan persentase $80 \%$ dan perilaku memakai kredit usahatani $80 \%$ dengan jumlah 24 petani memakai kredit usaha tani.

Tabel 1. Sikap dan Perilaku Petani Terhadap Kredit Usaha Tani(KUT).

\begin{tabular}{lccc}
\hline No & Jumlah(Petani) & Persentase $(\%)$ & Kategori \\
\hline 1. & 24 & $80 \%$ & Positif \\
2. & 6 & $20 \%$ & Negatif \\
\hline Jumlah & 30 & $100 \%$ & \\
\hline
\end{tabular}

\section{Hasil Analisis Tingkat Pengetahuan Petani Terhadap Kredit Usaha Tani.}

Tabel 20.Skor Tingkat Pengetahuan Petani Terhadap Kredit Usaha Tani.

\begin{tabular}{|c|c|c|c|c|}
\hline \multirow[t]{3}{*}{ Uraian } & \multicolumn{4}{|c|}{ Jawaban Responden } \\
\hline & \multirow[t]{2}{*}{ Tahu } & \multicolumn{3}{|c|}{ Tidak } \\
\hline & & $(\%)$ & Tahu & $(\%)$ \\
\hline $\begin{array}{l}\text { 1.KUT merupakan program pijaman yang } \\
\text { bisa diakses untuk usaha tani. }\end{array}$ & 28 & $\begin{array}{c}93,3 \\
\%\end{array}$ & 2 & $6,6 \%$ \\
\hline $\begin{array}{l}\text { 2.Program kredit pemerintah yang } \\
\text { menetapkan bunga hanya } 5 \% .\end{array}$ & 19 & $\begin{array}{c}63,3 \\
\%\end{array}$ & 11 & $36,6 \%$ \\
\hline $\begin{array}{l}\text { 3.Program kredit pembiayaan usaha tani } \\
\text { jangka waktu maksimal 5-6 tahun. }\end{array}$ & 23 & $\begin{array}{l}76,6 \\
\%\end{array}$ & 7 & $23,3 \%$ \\
\hline 4.Lahan dapat menjadi agunan usaha tani. & 28 & $\begin{array}{c}93,3 \\
\%\end{array}$ & 2 & $6,6 \%$ \\
\hline $\begin{array}{l}\text { 5.Angka plafon jumlah pinjaman program } \\
\text { kredit pembiayaan usaha tani } \\
\text { perseorangan mencapai } 50 \text { juta. }\end{array}$ & 23 & $\begin{array}{l}76,6 \\
\%\end{array}$ & 7 & $23,3 \%$ \\
\hline $\begin{array}{l}\text { 6.Angka plafon jumlah pinjaman program } \\
\text { kredit usaha tani kelompok tani } \\
\text { mencapai } 500 \text { juta. }\end{array}$ & 24 & $80 \%$ & 6 & $20 \%$ \\
\hline $\begin{array}{l}\text { 7.Pembayaran angsuran program } \\
\text { pinjaman/kredit bank ada yang dapat } \\
\text { dengan pembayaran angsuran per } \\
\text { periode panen.(jika panen baru dibayar) }\end{array}$ & 23 & $\begin{array}{l}76,6 \\
\%\end{array}$ & 7 & $23,3 \%$ \\
\hline
\end{tabular}


Dapat dilihat, dari tabel frekuensi tingkat pengetahuan petani di atas bahwa petani desa Pegagan Julu III memiliki persentase yang tinggi pada jawaban yang benar, artinya petani di desa penelitian memiliki pengetahuan yang baik terhadap kredit usaha tani.

Tabel 21.Tabel Frekuensi Pengetahuan Petani Responden

\begin{tabular}{llcl}
\hline No & Pengetahuan & Frekuensi(org) & Persentase(\%) \\
\hline 1 & Baik & 24 & $80 \%$ \\
2 & Kurang & 6 & $20 \%$ \\
\hline & Total & 30 & $100 \%$ \\
\hline
\end{tabular}

Sikap Perbankan Terhadap Calon Nasabah Petani yang Tidak Memiliki Agunan.

Berdasarkan hasil wawancara yang dilakukan dengan pihak bank, untuk mengetahui sikap bank terhadap petani yang tidak memiliki agunan adalah:

1) Pihak bank keberatan memberikan pinjaman kredit kepada petani yang tidak memiliki agunan,

2) Pihak bank menolak memberikan pinjaman kredit kepada petani yang tidak memiliki agunan,

Pihak bank memberikan saran agar petani mengambil kredit tanpa agunan (KTA).

\section{Kesimpulan}

Berdasarkan hasil penelitian, diperoleh kesimpulan sebagai berikut :

1. Sikap petani terhadap kredit usaha tani (KUT) di Desa Pegagan Julu III adalah positif. Perilaku petani terhadap kredit usaha tani juga positif dengan perolehan persentase jumlah pengguna kredit $80 \%$.

2. Tingkat pengetahuan petani terhadap mekanisme perolehan kredit di Desa Pegagan Julu III sangat baik dengan perolehan persentase $80 \%$ petani memiliki tingkat pengetahuan yang baik.

3. Sikap perbankan terhadap calon nasabah yang tidak memiliki agunan sebaiknya mengikuti program kredit tanpa agunan (KTA) agar petani tetap dapat bantuan kredit tanpa agunan.

\section{Daftar Pustaka}

Amanda BT, 2013, Teori Pisikologi Sosial, Paper ;Makasar, Universitas Hasanuddin.

Azwar, Saifuddin. 2007. Sikap Manusia.Pustaka Pelajar: Yogyakarta.

Basu Swastha dan Hani Handoko, Manajemen Perusahaan Analisa Perilaku

Boediono. 1999, Teori Pertumbuhan Ekonomi, Yogyakarta: BPFE

Handoko, T. Tani, 2005, Manajemen Personalia dan Sumber Daya Manusia, B.P.F.E UGM, Yogyakarta.

Hasibuan, Malayu S. P. 2006, Manajemen Sumber Daya Manusia, Edisi Revisi : Jakarta. Bumi AksaraKonsumen, Yogyakarta : Liberty Edisi Pertama 
Mokhamad Arwani, dkk, 2011. Peran Karakteristik Individu Sebagai Moderator Pengaruh Kepuasan, Kepercayaan dan Komitmen Terhadap Loyalitas (Studi pada Nasabah Bank Syariah di Kabupaten Kudus)", Jurnal Sosial dan Budaya, Vol. 4 Nomor 2, Desember, 2011, hlm. 159-170.

Nurul Widyawati, 2008. Pengaruh Kepercayaan dan Komitmen Serta Bauran Pemasaran Jasa terhadap Loyalitas Konsumen di Hotel Zakiyah Medan", Jurnal Ekitas, Vol. 12, 2008, hlm. 74-96.

Schiffman, Leon. G; Leslie Lazar Kanuk. 2004. Consumer Behavior. New Jersey : Pearson Prentice Hall,Inc.

Natoatmodjo, Soekidjo, 2003. Pendidikan dan Prilaku. Jakarta. Rineka Cipta. h. 3

Sumarni, Murti dan John Soeprihanto. 2005. Pengantar Bisnis. Liberty. Yogyakarta.

Ujang Sumarwan, Perilaku Konsumen, 2011. Teori dan Penerapannya dalam Pemasaran, Ghalia Indonesia, Bogor, hlm. 165-166. 